\title{
HUBUNGAN PENGETAHUAN TENTANG KARIES GIGI DENGAN INDEKS DMF-T IBU-IBU RUMAH TANGGA DI KELURAHAN TERNATE TANJUNG LINGKUNGAN II KOTA MANADO.
}

\author{
Anneke Tahulending ${ }^{1}$,Jeanne d'Arc Zavera Adam ${ }^{2}$ \\ 1,2 ) Jurusan Keperawatan Gigi Poltekkes Kemenkes Manado
}

Email : anneke@gmail.com

\begin{abstract}
ABSTRAK
Latar Belakang :. Pengetahuan mengenai kesehatan gigi dan mulut sangat penting agar terhindar dari masalah kesehatan gigi dan mulut khususnya karies gigi. Tujuan : Untuk mengetahui hubungan pengetahuan tentang karies gigi dengan indeks DMF-T pada ibu-ibu rumah tangga di Kelurahan Ternate Tanjung Lingkungan II Kota Manado.Metode: Penelitian ini menggunakan metode analitik dengan pendekatan cross sectional study dengan mengukur pengetahuan dan indeks DMFT ibu-ibu rumah tangga yangberlokasi di Kelurahan Ternate Tanjung Lingkungan II Kota Manado. Sampel yang digunakan yaitu 71 ibu-ibu rumah tangga, dengan tekhnik pengambilan sampel yaitu simple random sampling. Instrument penelitian yang digunakan adalah kuesioner terstruktur untuk mengukur pengetahuan tentang karies gigi serta pemeriksaan status kesehatan gigi (DMF-T). Data yang diperoleh ditabulasi dan diuji menggunakan chi squareuntuk melihat hubungan pengetahuan tentang karies gigi dengan indeks DMF-T. Hasil : Hasil penelitian ini menunjukan responden memiliki pengetahuan dan DMF-T kategori baik berjumlah 19 responden, pengetahuan kategori baik sedangkan DMF-T nya buruk berjumlah 13 responden, pengetahuan kategori kurang baik dan DMF-T nya baik berjumlah 8 responden, dan pengetahuan kurang baik DMF-T buruk berjumlah 31 responden. Hasil analisis menggunakan uji chi square pada tingkat kemaknaan $95 \%(\alpha=0,05)$, menunjukan nilai p $0,002<\alpha 0,05$. Kesimpulan : ada hubungan yang signifikan antara pengetahuan tentang karies gigi dengan indeks DMF-T pada ibuibu rumah tangga di Kelurahan Ternate Tanjung Lingkungan II Kota Manado.
\end{abstract}

Kata kunci : Pengetahuan, Karies Gigi, Indeks DMF-T

\begin{abstract}
Background :. Knowledge of dental and oral health is very important to avoid dental and oral health problems, especially dental caries. Objective: To determine the relationship of knowledge about dental caries with the DMF-T index in housewives in Ternate Tanjung Lingkungan II City of Manado City. Method: This study used an analytical method with a cross sectional study approach by measuring knowledge and DMFT index of mothers households located in Ternate Tanjung Lingkungan II Village, Manado City. The sample used is 71 housewives, with the sampling technique that is simple random sampling. The research instrument used was a structured questionnaire to measure knowledge about dental caries and examination of dental health status (DMF-T). The data obtained were tabulated and tested using chi square to see the relationship of knowledge about dental caries with the DMF-T index. Results: The results of this study showed that respondents had knowledge and DMF-T in the good category amounting to 19 respondents, knowledge was good while the DMF-T was 13 respondents, the knowledge of the categories was poor and the DMF-T was 8 respondents, and knowledge was poor Bad DMF-T numbered 31 respondents. The results of the analysis used the chi square test at a significance level of $95 \%(\alpha=0.05)$, showing a $\mathrm{p}$ value of $0.002<\alpha 0.05$. Conclusion: there is a significant
\end{abstract}


relationship between knowledge about dental caries and DMF-T index in housewives in Ternate Tanjung Lingkungan II Village, Manado City.

Keywords: Knowledge, Dental Caries, DMF-T Index

\section{PENDAHULUAN}

Pengetahuan merupakan sesuatu yang sangat penting untuk terbentuknya tindakan seseorang. Pengetahuan mengenai kesehatan gigi dan mulut sangat penting agar supaya kita terhindar dari masalah kesehatan gigi dan mulut ${ }^{1}$. Penyebab timbulnya masalah kesehatan gigi dan mulut antara lain yaitu faktor perilaku atau sikap mengabaikan kesehatan gigi dan mulut. Hal tersebut dilandasi oleh kurangnya pengetahuan masyarakat akan pentingnya pemeliharaan kesehatan gigi dan mulut ${ }^{2}$

Karies gigi merupakan suatu proses demineralisasi struktur jaringan keras seperti enamel dan dentin. Karies gigi atau gigi berlubang merupakan masalah kesehatan gigi dan mulut yang sering dialami oleh hampir seluruh masyarakat indonesia. Pada Riset Kesehatan Dasar RISKESDAS (2007) prevalensi masyarakat indonesia yang pernah mengalami karies yaitu $72,1 \%$, sedangkan prevalensi masyarakat di provinsi sulawesi utara menunjukan angka yang lebih tinggi yaitu $82,8 \% .^{3}$.

Usia dan jenis kelamin merupakan faktor yang mempengaruhi angka kejadian karies, tingginya angka kejadian karies gigi dapat dihitung dengan Indeks DMF-T. Indeks DMF-T merupakan indikator status kesehatan gigi yang menunjukan banyaknya kerusakan gigi yang dialami oleh seseorang. Nilai DMF-T merupakan penjumlahan nilai dari indeks D-T, M-T, dan F-T, yang menunjukan banyaknya kerusakan gigi yang pernah dialami seseorang baik berupa Decay/D (gigi karies), Missing/M (gigi yang dicabut karena karies, dan Filling/F (gigi yang telah ditambal karena karies). Menurut RISKESDAS 2013, Indeks DMF-T di Indonesia sebesar 4,6 yang berarti rata-rata kerusakan gigi setiap orang yaitu sebanyak 5 gigi. Indeks DMF-T ditemukan lebih tinggi pada perempuan $(4,9)$ dibanding laki-laki $(4,1)^{4}$

Hasil penelitian Sosiawan dkk (2016) mendapatkan bahwa kategori DMF-T ibuibu yang berusia 41-45 tahun memiliki nilai indeks DMF-T diatas rata-rata yang lebih tinggi dari pada ibu-ibu yang berusia 36-40 tahun. Hasil ini sesuai dengan teori bahwa seiring dengan bertambahnya usia maka angka kejadian karies dan gigi hilang meningkat. ${ }^{5}$

Hasil penelitian yang dilakukan oleh Tolingguhu (2013) menjelaskan bahwa ada hubungan yang signifikan antara pengetahuan dengan karies gigi dimana yang memiliki pengetahuan kurang berjumlah 13 orang dan semuanya mengalami kejadian karies gigi dengan kategori kurang baik sedangkan untuk pengetahuan yang baik berjumlah 33 orang dimana 16 orang yang mengalami kejadian karies gigi kategori kurang baik dan 17 orang mengalami kejadian karies gigi kategori baik. ${ }^{6}$

Berdasarkan data Puskesmas Kombos bulan januari sampai maret 2018 terdapat 89 kunjungan penduduk ke Puskesmas Kombos, didapatkan 52 kunjungan penduduk wanita yang diantaranya adalah ibu-ibu rumah tangga dari Kelurahan Ternate Tanjung dan 37 kunjungan penduduk laki-laki, dan diantara 52 kunjungan terdapat 46 kunjungan mengalami karies gigi.

Hasil survei awal yang dilakukan oleh peneliti pada tanggal 14 April 2018 di 
Kelurahan Ternate Tanjung Lingkungan II Kecamatan Singkil Kota Manado, terdapat 268 Kepala Keluarga, 249 ibu rumah tangga dan 1112 Jiwa yang terdiri dari 614 Lakilaki, 498 Perempuan. Hasil tanya jawab pada 9 ibu-ibu di Kelurahan Ternate Tanjung Lingkungan II mengenai pencegahan karies gigi hanya 3 orang yang tahu cara mencegah karies gigi, 4 ibu-ibu mempunyai kebiasaan menyikat gigi 2 kali sehari sedangkan 5 ibuibu 1 kali sehari yaitu hanya pada waktu mandi saja, mereka juga jarang mendengar penyuluhan tentang kesehatan gigi dan mulut. Dari hasil pemeriksaan gigi yang dilakukan pada 9 ibu-ibu semuanya mengalami karies gigi $>3$ (DMF-T) dengan nilai rata-rata $\mathrm{D}=6,1 \mathrm{M}=3,9 \mathrm{~F}=0,4$ dengan rata-rata nilai $\mathrm{DMFT}=10,4$ menurut $\mathrm{WHO}$ (2013) indeks ini tergolong dalam kategori sangat tinggi. Hal ini terjadi kemungkinan karena faktor ketidaktahuan atau kurangnya pengetahuan tentang kesehatan gigi dan mulut. ${ }^{4}$

Berdasarkan uraian tersebut diatas, maka penulis tertarik untuk melakukan penelitian guna mengetahui hubungan pengetahuan tentang karies gigi dengan Indeks DMF-T pada ibu-ibu rumah tangga di Kelurahan Ternate Tanjung Lingkungan II Kota Manado.

Menurut Notoatmodjo

Pengetahuan merupakan hasil dari tahu, dan ini terjadi setelah orang melakukan penginderaan terhadap suatu objek tertentu. Penginderaan terjadi melalui panca indera manusia, yakni indera penglihatan, pendengaran, penciuman, rasa, dan raba. Sebagian besar pengetahuan manusia diperoleh melalui mata dan telinga. Pengetahuan atau kognitif merupakan domain yang sangat penting dalam melakukan tindakan seseorang. ${ }^{2}$ Menurut Budiharto (2010) Pengetahuan merupakan ranah kognitif yang mempunyai 6 tingkatan :
1) Tahu (know), tahu merupakan tingkat pengetahuan yang paling rendah, misalnya mengingat atau mengingat kembali suatu objek atau rengsangan tertentu, 2) Memahami (comprehension), memahami adalah kemampuan untuk menjelaskan secara benar objek yang diketahui, 3) Aplikasi (application), aplikasi yaitu kemampuan untuk menggunakan materi yang telah dipelajari pada situasi dan kondisi sebelumnya, 4) Analisis (analysis), kemampuan untuk menjabarkan suatu materi atau objek kedalam komponen-komponen tetapi masih didalam suatu struktur organisasi tersebut, 5) Sintesis (synthesis), sintesis yaitu kemampuan untuk menggabungkan bagian-bagian ke dalam suatu bentuk tertentu yang baru, 6) Evaluasi (evaluation) evaluasi yaitu kemampuan untuk melakukan penilaian terhadap suatu objek tertentu. ${ }^{7}$

Karies gigi adalah kerusakan yang terbatas pada jaringan gigi mulai dari email gigi hingga menjalar ke dentin. Struktur email sangat menentukan proses terjadinya karies gigi. Permukaan email luar lebih tahan terhadap karies dibanding lapisan dibawahnya, karena lebih padat dan lebih keras. ${ }^{8}$ Karies gigi adalah hasil interaksi dari bakteri di permukaan gigi, plak dan diet (khususnya komponen karbohidrat yang dapat difermentasikan oleh bakteri plak menjadi asam, terutama asam laktat dan asetat). Sehingga terjadi demineralisasi jaringan keras gigi dan memerlukan cukup waktu untuk kejadiannya. ${ }^{9}$ Menurut aktor yaitu host (pejamu), agent (bakteri), Bahar (2011) penyebab terjadinya karies meliputi empat dan enviroment (substrat) serta waktu $^{10}$.

a. Host (pejamu)

Pit dan fissure pada gigi posterior sangat rentan terhadap karies karena sisa-sisa makanan mudah menumpuk di daerah 
tersebut terutama pit dan fissure yang dalam. Selain itu, permukaan gigi yang kasar juga dapat menyebabkan plak mudah melekat dan membantu perkembangan karies ${ }^{11 .}$

b. Agent (bakteri)

Plak gigi merupakan deposit lunak yang melekat erat pada permukaan gigi, terdiri atas mikroorganisme yang berkembang biak dalam suatu matrik intraseluler jika seseorang melalaikan kebersihan gigi dan mulutnya. Plak biasanya mulai terbentuk pada sepertiga permukaan gingival dan pada permukaan gigi yang cacat dan kasar.

Streptococcus muutans adalah penyebab utama karies gigi pada mahkota karena sifatnya yang menempel pada email, menghasilkan dan dapat hidup di lingkungan asam, berkembang pesat di lingkungan yang kaya sukrosa, dan menghasilkan bakteriosin. ${ }^{9}$

\section{c. Enviroment (substrat)}

Makanan sangat berpengaruh terhadap gigi dan mulut, Makanan yang bersifat fermentasi karbohidrat lebih signifikan memproduksi asam, diikuti oleh demineralisasi email. Tidak semua karbohidrat benar-benar kariogenik. Karbohidrat kompleks seperti gandum relatif lebih tidak berbahaya karena tidak secara sempurna dihancurkan dalam rongga mulut, tetapi molekul karbohidrat yang rendah dengan mudah bersatu dengan plak dan di metabolisme secara cepat oleh bakteri. $^{12}$

Menurut Organisasikan Kesehatan dunia (WHO, karies gigi dapat diartikan sebagai suatu proses patologi pascaerupsi yang terlokalisasi dan disebabkan oleh faktor luar. Proses ini dimulai dengan kerusakan jaringan email yang menjadi lunak dan pada akhirnya menyebabkan terjadinya kavitas. Penyebab terjadinya karies gigi dianut empat faktor yang mempengaruhinya. Keempat faktor tersebut berlandaskan pada tiga faktor utama yaitu host (pejamu), agent (mikrofora), dan environment (substrat). Terjadinya karies gigi disebabkan karena sinergi dari ketiga faktor tersebut dan didukung oleh faktor keempat yaitu faktor waktu ${ }^{10}$

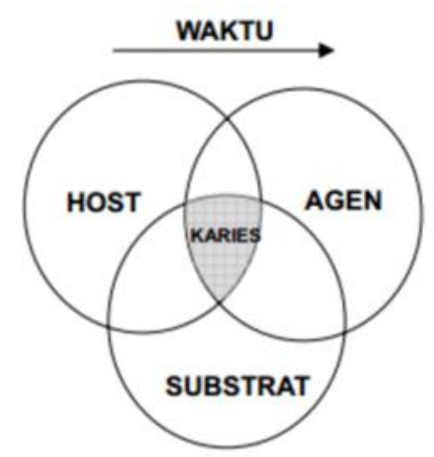

Indeks DMF-T merupakan penjumlahan dari komponen $D-T, M-T$, dan $F-T$ yang menunjukan banyaknya kerusakan gigi yang pernah dialami seseorang, baik berupa :

Decay/D (merupakan jumlah gigi permanen yang mengalami karies dan belum diobati atau ditambal), Missing/M (jumlah gigi permanen yang dicabut atau masih berupa sisa akar), dan Filling/ $F$ adalah jumlah gigi permanen yang telah dilakukan penumpatan atau ditambal. ${ }^{4}$

Menurut WHO (World Health Organization), Indeks DMF-T adalah indeks untuk menilai status kesehatan gigi dan mulut dalam hal karies pada gigi permanen, baik $\leq 3$ dan buruk $>3$. $^{13}$

\section{Rumus DMF-T :}

$\mathrm{DMF}-\mathrm{T}=\mathrm{D}($ Decay $)+($ Missing $)+($ Filling $)$ 
Tujuan penelitian yaitu untuk mengetahui hubungan pengetahuan tentang karies gigi dengan indeks DMF-T pada ibuibu rumah tangga di Kelurahan Ternate Tanjung Lingkungan II Kota Manado.

Hasil penelitian ini diharapkan dapat memberikan masukan dan manfaat bagi perkembangan ilmu pengetahuan dibidang Kesehatan Gigi dan Mulut yang berkaitan dengan hubungan pengetahuan tentang karies gigi dengan indeks DMF-T pada ibuibu di Kelurahan Ternate Tanjung Lingkungan II Kota Manado.

\section{METODOLOGI}

Penelitian ini menggunakan jenis penelitian yang bersifat analitik yaitu mencari hubungan antara faktor resiko dan faktor efek dengan cara pendekatan cross sectionalstudy dimana observasi atau pengumpulan data variabel bebas atau resiko dan variabel terikat atau akibat dilakukan secara bersama-sama atau sekaligus. ${ }^{2}$ Waktu penelitian dilaksanakan pada minggu 3 bulan Juni 2018, tempat penelitian di Kelurahan Ternate Tanjung Lingkungan II Kota Manado.

\section{Variabel Penelitian}

1. Variabel bebas : Pengetahuan tentang karies gigi

2. Variabel terikat: Indeks DMF-T

\section{Definisi Operasional}

1. Pengetahuan adalah untuk melihat sejauh mana seorang ibu mengetahui dan memahami tentang karies gigi. Pengetahuan diukur dengan menggunakan kuesioner yang telah diuji validitas terlebih dahulu. Pengetahuan diukur dengan menggunakan kuesioner yang terdiri dari 14 pertanyaan yang terdiri dari 12 pertanyaan positif (favorable) soal no. 1, 2, 3, 4, 5, 6, 7, 8, $9,10,11,12$ dan 2 pertanyaan negatif (unfavorable) soal no. 13 dan 14dengan 2 alternatif jawaban yaitu benar dan salah. Pernyataan positif (favorable) dengan nilai penilaian jika jawaban benar diberi nilai 2 dan jawaban salah diberi nilai 1, sebaliknya untuk pernyataan negatif (unfavorable) dengan penilaian jawaban benar diberi nilai 1 dan salah diberi nilai 2. Pengetahuan baik bila nilai pengetahuan responden 22-28dan pengetahuan kurang baik bila nilai pengetahuan responden 14-21.

2. Indeks DMF-T adalah indeks untuk mengukur karies gigi ibu-ibu rumah tangga di Kelurahan Ternate Tanjung, pengukuran Indeks DMF-T yaitu dengan melakukan pemeriksaan karies gigi dan mencatat pada format DMF-T, alat yang digunakan dalam pemeriksaan karies gigi yaitu kaca mulut, sonde, excavator dan pinset dimana karies gigi dengan kategori baik jika $\leq 3$ dan karies gigi dengan kategori buruk jika $>3$.

Pengambilan sampel dilakukan dengan teknik Simple Random Sampling, yaitu dengan cara door to door secara acak pada ibu-ibu di Kelurahan Ternate Tanjung Lingkungan II Kota Manado dan jumlah sampel pada penelitian ini adalah 71 responden. Jumlah sampel dihitung dengan menggunakan rumus populasi yang sudah diketahui.

Rumus yang digunakan ialah :

$$
\mathrm{n}=\frac{\mathrm{N}}{1+\mathrm{N}\left(\mathrm{d}^{2}\right)}
$$

Dimana $\mathrm{N}=$ Jumlah Populasi

$\mathrm{n}=$ Jumlah sampel yang dicari

$\mathrm{d}^{2}=$ Presisi yang ditetapkan $10 \%$

Penyelesaian :

$$
\mathrm{n}=\frac{\mathrm{N}}{1+\mathrm{N}\left(\mathrm{d}^{2}\right)}
$$




$$
\begin{aligned}
& =\frac{249}{1+249\left(0,1^{2}\right)} \\
& =\frac{249}{1+249(0,01)} \\
& =\frac{249}{1+2,49} \\
& =\frac{249}{3,49}
\end{aligned}
$$

= 71,34 dibulatkan menjadi 71 responden. Dengan kriteria inklusi yaitu:Ibu-ibu rumah tangga yang bersedia menjadi responden, dan ibu -ibu rumah tangga usia $<46$ tahun.

Data yang diperoleh kemudian ditabulasi dan dianalisis untuk melihat hubungan pengetahuan tentang karies gigi dengan indeks DMF-T, maka digunakan uji Chi Square dan diolah dengan menggunakan perangkat lunak statistik komputer

\section{HASIL}

1. Distribusi responden menurut golongan umur

Distribusi responden menurut umur dapat dilihat pada tabel 1 dibawah ini

Tabel 1. Distribusi Responden Menurut Golongan Umur

\begin{tabular}{cll}
\hline Umur & $\mathrm{n}$ & $\%$ \\
\hline 25-31 Tahun & 27 & 38 \\
32-38 Tahun & 23 & 32 \\
39-45 Tahun & 21 & 30 \\
\hline Total & 71 & 100 \\
\hline
\end{tabular}

Distribusi responden menurut golongan umur pada tabel 1 menunjukkan jumlah responden terbanyak pada golongan umur 25-31 tahun yaitusebanyak 27 responden (38\%) dan yang lainnya umur 32-38 tahun 23 responden (32\%), umur 39-45tahun 21 responden $(30 \%)$.

2. Distribusi responden berdasarkan tingkat pengetahuan

Distribusi responden berdasarkan tingkat pengetahuandapat dilihat pada tabel 2 di bawah ini :

Tabel 2. Distribusi Responden Berdasarkan Tingkat Pengetahuan

\begin{tabular}{ccc}
\hline Pengetahuan & $\mathrm{n}$ & $\%$ \\
\hline Baik & 32 & 45 \\
Kurang Baik & 39 & 55 \\
\hline Total & 71 & 100 \\
\hline
\end{tabular}

Berdasarkan data pada tabel 2 pengetahuan responden sebagian besar terdapat pada kriteria pengetahuan kurang baik yaitu 39 responden $(55 \%)$ dan pengetahuan baik sebanyak 32 responden $(45 \%)$.

3. Distribusi responden berdasarkan kategori DMF-T

Distribusi responden berdasarkan kategori DMF-T dapat dilihat pada tabel 3 di bawah ini :

Tabel 3. DistribusiResponden Berdasarkan Kategori DMF-T

\begin{tabular}{ccc}
\hline Indeks & $\mathrm{n}$ & $\%$ \\
DMF-T & 27 & 38 \\
\hline Baik & 62 \\
Buruk & 44 & 100 \\
\hline Total & 71 & \\
\hline
\end{tabular}

Data pada tabel 3 yang diperoleh dari hasil pemeriksaan DMF-T menyatakan bahwa sebagian besar responden termasuk dalam kriteria buruk dengan jumlah 44 responden (62\%), dan kategori baiksebanyak 27 responden $(38 \%)$.

Distribusi kriteria DMF-T berdasarkan tingkat pendidikan dapat dilihat pada tabel 4 di bawah ini : 
Tabel 4. Distribusi Kriteria DMF-T Berdasarkan Tingkat Pendidikan

\begin{tabular}{ccccccc}
\hline $\begin{array}{c}\text { Tingkat } \\
\text { Pendidikan } \\
\begin{array}{c}\text { Wajib } \\
\text { Belajar }\end{array}\end{array}$ & Baik & $\%$ & Buruk & $\%$ & Total & $\%$ \\
\cline { 2 - 5 } SMP & 6 & 8 & 13 & 19 & 19 & 27 \\
SMA & 21 & 30 & 31 & 43 & 52 & 73 \\
\hline Total & 27 & 38 & 44 & 62 & 71 & 100 \\
\hline
\end{tabular}

Distribusi kriteria DMF-T berdasarkan tingkat pendidikan pada tabel 4 menunjukkan bahwa tingkat pendidikan SMA dengan kriteria DMF-T buruk sebanyak 31 responden (43\%) sedangkan kriteria DMF-T baik sebanyak 21 responden (30\%), tingkat pendidikan SMP dengankriteria DMF-T buruk sebanyak 13 responden (19\%) sedangkan kriteria DMF-T baik sebanyak 6 responden ( $8 \%)$.

4. Distribusi responden berdasarkan hubungan pengetahuan dengan indeks DMF-T

Distribusi responden berdasarkan hubungan pengetahuan dengan indeks DMF-T dapat dilihat pada tabel 5 di bawah ini :

Tabel 5. Hubungan Pengetahuan Dengan Indeks DMF-T

\begin{tabular}{ccccccccc}
\hline & \multicolumn{9}{c}{ Indeks DMF-T } & & & \\
\cline { 2 - 5 } $\begin{array}{c}\text { Pengetahu } \\
\text { an }\end{array}$ & $\begin{array}{l}\text { Bai } \\
\mathrm{k}\end{array}$ & $\%$ & $\begin{array}{c}\text { Buru } \\
\mathrm{k}\end{array}$ & $\%$ & Ttl & $\%$ & $\alpha$ & $P$ \\
\hline Baik & 19 & 27 & 13 & 18 & 32 & 45 & 0,05 & 0,002 \\
$\begin{array}{c}\text { Kurang } \\
\text { Baik }\end{array}$ & 8 & 11 & 31 & 44 & 39 & 55 & & \\
\hline Total & 27 & 38 & 44 & 62 & 71 & $\begin{array}{c}10 \\
0\end{array}$ & \\
\hline
\end{tabular}

Berdasarkan data pada tabel 5 yaitu hubungan pengetahuan dengan indeks DMF$\mathrm{T}$ sebagian besar terdapat pada kriteria pengetahuan kurang baik dengan indeks DMF-T buruk sebanyak 31 responden (44\%), untuk pengetahuan kriteria baik dan indeks DMF-T kriteria baik sebanyak 19 responden (27\%), pengetahuan baik dan indeks DMF-T buruk sebanyak 13 responden (18\%), sedangkan pengetahuan kurang baik dan indeks DMF-T baik sebanyak 8 responden $(11 \%)$.

\section{PEMBAHASAN}

Pengetahuan orang tua berperan penting dalam tercapainya perilaku untuk mencegah terjadinya karies gigi. Secara umum pengetahuan dan perilaku orang tua yang baik memiliki hubungan terhadap baiknya jumlah karies gigi. Kesehatan gigi dan mulut termasuk didalamnya pencegahan terjadinya karies gigi. Masalah yang sering ditemui dan juga berpeluang menimbulkan penyakit karies adalah faktor perilaku, pengetahuan, sikap dan tindakan seseorang dalam memelihara kesehatan gigi dan mulut. ${ }^{14}$

Berdasarkan hasil penelitian pada ibu-ibu rumah tangga dengan jumlah responden 71 dengan kategori usia pada penelitian ini paling banyak dari usia 25-31 tahun sebanyak 27 responden (38\%). Untuk jenjang pendidikan menunjukan bahwa paling banyak responden berada pada jenjang pendidikan SMA sebanyak 52 responden $(73 \%)$.

Hasil penelitian yang diperoleh dari tabel 4 menunjukan bahwa DMF-T rata-rata lebih rendah pada ibu-ibu rumah tangga dengan tingkat pendidikan SMA bila dibandingkan dengan tingkat pendidikan SMP. Hasil penelitian Prihastari, dkk (2017) ada hubungan antara tingkat pendidikan dengan indeks DMF-T, dimana DMF-T rata-rata lebih rendah pada tingkat pendidikan tinggi dibandingkan tingkat pendidikan rendah. Seseorang dengan tingkat pendidikan yang tinggi akan memiliki pengetahuan yang baik tentang kesehatan yang akan mempengaruhi 
perilakunya sehingga mau merawat dan memelihara kesehatan gigi dan mulutnya. ${ }^{17}$

Berdasarkan hasil yang diperoleh dari tabel 5 terlihat pengetahuan responden dengan indeks DMF-T dalam kategori "baik" sebanyak 19 responden (27\%).Pengetahuan merupakan ranah yang sangat penting untuk terbentuknya tindakan seseorang, semakin baik pengetahuan yang dimiliki seseorang dengan diikuti kesadaran dan perilaku dengan baik maka kemungkinan dapat mencegah terjadinya gigi berlubang. Budiharto (2010), menyatakan bahwa seseorang memperoleh pengetahuan melalui penginderaan terhadap objek tertentu. Pengetahuan diperoleh sebagai akibat stimulus yang ditangkap pancaindera. Pengetahuan bisa diperoleh secara alami maupun secara terencana yaitu melalui proses pendidikan. ${ }^{7}$ Pengetahuan responden "baik" sedangkan indeks DMF-T dalam kategori "buruk" sebanyak 13 responden (18\%), ini menandakan walaupun pengetahuannya baik tetapi tidak diikuti oleh kesadaran untuk menjaga kesehatan gigi dan mulutnya maka akan mempengaruhi kejadian karies giginya tidak baik. Hal ini terjadi karena pengetahuan saja tidak cukup mendukung seseorang memiliki kesehatan gigi dan mulut yang baik, karena harus diimbangi dengan sikap dan tindakan yang positif. Pendidikan kesehatan gigi adalah bagian dari pendidikan kesehatan yang merupakan suatu proses belajar yang ditujukan kepada individu dan kelompok masyarakat serta bertujuan untuk meningkatkan pengertian dan kesadaran masyarakat tentang pentingnya memelihara kesehatan gigi dan mulut. ${ }^{15}$

Pengetahuan responden dengan indeks DMF-T dalam kategori "kurang baik" sebanyak 31 responden (44\%). Hal ini menunjukkan bahwa semakin baik pengetahuan dan kesadaran seseorang akan membuat kondisi giginya baik, sebaliknya pengetahuannya tidak baik maka akan mempengaruhi status kesehatan gigi yaitu karies gigi.

Pengetahuan responden "kurang baik" dengan indeks DMF-T dalam kategori "baik" sebanyal 8 responden (11\%). Hal ini menunjukan selain pengetahuan masih ada faktor lain yang bisa menyebabkan karies gigi. Menurut Irma Z, dkk (2013) bahwa karies gigi disebabkan oleh 3 faktor / komponen yang saling berinteraksi yaitu komponen dari gigi dan air ludah, komponen mikroorganisme yang ada didalam mulut yang mampu menghasilkan asam, komponen makanan yang mengandung karbohidrat seperti glukosa dan sukrosa yang dapat diragikan oleh bakteri sehingga terbentuklah asam. $^{16}$

Berdasarkan hasil penelitian melalui tabulasi secara silang dengan menggunakan analisis statistik uji chi squarediperoleh nilai $\mathrm{p}=0,002$. Dengan menggunakan tingkat kepercayaan 95\% $(\alpha=5 \%)$ maka nilai $\mathrm{p}=$ 0,002< 0,05 maka $\mathrm{H}_{0}$ ditolak dan $\mathrm{H}_{1}$ diterima. Sehingga dalam penelitian ini terdapat hubungan yang bermakna antara pengetahuan tentang karies gigi dengan indeks DMF-T pada ibu-ibu rumah tangga di Kelurahan Ternate Tanjung Kota Manado.

Penelitian ini sejalan dengan hasil penelitian sebelumnya oleh Jayanti (2012) bahwa terdapat hubungan yang signifikan antara pengetahuan ibu tentang karies gigi dengan kerjadian karies gigi, yaitu semakin tinggi tingkat pengetahuan ibu maka kejadian karies gigi semakin rendah. ${ }^{17}$

\section{KESIMPULAN}

Berdasarkan penelitian yang telah dilakukan pada ibu-ibu rumah tangga di Kelurahan 
Ternate Tanjung Lingkungan II Kota Manadodiperoleh hasil bahwa ada hubungan yang signifikan antara pengetahuan karies gigi dengan indeks DMF-T.

\section{Saran}

Setelah melaksanakan penelitian dan membahas hasil penelitian ini, peneliti dapat memberikan saran :

1. Kepada seluruhibu-ibu rumah tangga agar dapat membiasakan diri menjaga kesehatan gigi dan mulut dengan cara menyikat gigi secara teratur yaitu 2 kali sehari, pagi setelah sarapan pagi dan malam sebelum tidur, mengurangi makanan manis, mudah melekat dan makanan asam, serta rajin memeriksakan gigi setiap enam bulan sekali ke Puskesmas atau Dokter gigi terdekat, serta dapat berkumur-kumur setelah selesai makan.

2. Kepada ibu-ibu rumah tangga yang mempunyai status DMF-T yang tinggi disarankan agar datang ke puskesmas terdekat untuk mendapatkan tindakan perawatan lebih lanjut pada kasus yang sudah ada.

\section{DAFTAR PUSTAKA}

1. Rahmadhan, G. (2010). Serba Serbi Kesehatan Gigi dan Mulut. Bukune. Jakarta

2. Notoatmodjo, S. (2007). Kesehatan Masyarakat Ilmu dan Seni. Rineka Cipta. Jakarta

3. Depkes, RI. (2007). Riset Kesehatan Dasar.Badan Penelitian dan Pengembangan Tenaga Kesehatan Department Kesehatan. Jakarta

4. Kemenkes, RI. (2013). Riset Kesehatan Dasar.Badan Penelitian
Pengembangan Tenaga Kesehatan Department Kesehatan. Jakarta

5. Sosiawan, A., Herosoebekti, R., Hapsoro, A., Santosa, L., (2016). Gambaran Tingkat Keparahan Karies Gigi Pada Ibu-Ibu Usia 36-45 Tahun Dusun Claket Desa Claket Kecamatan Pacet Kabupaten Mojokerto. Diakses pada tanggal 12 Mei 2018

6. Tolingguhu, D. (2013). Hubungan Pengetahuan Kesehatan Gigi dan Mulut Dengan Kejadian Karies Gigi Permanen Pada Pengunjung Poli Gigi Puskesmas Bahu Kecamatan Malalayang.Jurusan Keperawatan Gigi Politenik Kesehatan Kemenkes Manado. Manado.

7. Budiharto., (2010). Pengantar Ilmu Perilaku Kesehatan dan Pendidikan Kesehatan Gigi. EGC. Jakarta

8. Hermawan, R. (2010). Menyehatkan Daerah Mulut.Buku Biru. Jogjakarta.

9. Putri, M. H., Herijulianti, E., \& Nurjanah, N., (2010). Ilmu Pencegahan Penyakit Jaringan Keras dan Pendukung Gigi. Rineka Cipta. Jakarta.

10. Bahar, A. (2011). Paradigma Baru Pencegahan Karies Gigi.Lembaga Penerbit Fakultas Ekonomi Universitas Indonesia. Jakarta.

11. Pintauli, Sondang., Hamada, Taizo., (2008). Menuju Kesehatan Gigi dan Mulut Sehat : Pencegahan dan Pemeliharaan. USU Press. Medan. Hal 5

12. Tarigan, R. (2013). Karies Gigi Edisi 2. EGC. Jakarta

13. Notoharjo, I. T., \& Magdarina, D. A., (2013). Penilaian Indeks DMF-T Anak Usia 12 Tahun Oleh Dokter Gigi dan Bukan Dokter Gigi di Kabupaten Ketapang Provinsi Kalimantan Barat. Diakses pada tanggal 12 Mei 2018

14. Astoeti, T. E. (2006). Total Quality Management dalam Pendidikan 
Kesehatan Gigi di Sekolah.PT Raja

Grafindo. Jakarta.

15. Herijulianti, E., Indriani, T.S., \& Artini, S. (2002).Pendidikan Kesehatan Gigi. EGC. Jakarta.

16. Irma, Z. Indah., \& Intan S.A. (2013). Penyakit Gigi Mulut dan THT. Penerbit Nuha Medika. Yogyakarta

17. Jayanti, Cahaya. (2012). Hubungan Tingkat Pengetahuan Ibu Tentang Karies Gigi Dengan Kejadian Karies Gigi Pada Anak TK Asyiyah Kataguhanan Sawit Boyolali. Fakultas Ilmu Kesehatan Masyarakat Universitas Muhammadiyah Surakarta. Surakarta. 